\title{
Canadian Immunization Guide: "Anaphylaxis and other acute reactions following vaccination" chapter update
}

\author{
Natalie Dayneka ${ }^{1,2}$, Christina Jensen ${ }^{3}$, Kyla Hildebrand ${ }^{4,5}$ on behalf of the National Advisory \\ Committee on Immunization (NACl)*
}

\begin{abstract}
Background: The Canadian Immunization Guide (CIG) is a comprehensive resource on immunization for health professionals and vaccine program decision-makers. It is developed based on the evidence-based recommendations of the National Advisory Committee on Immunization (NACl). The NACI Vaccine Safety Working Group (VSWG) is comprised of $\mathrm{NACl}$ members, liaison members and external experts. The World Allergy Organization now recommends that antihistamines should not be used in the initial treatment of anaphylaxis. The update of the chapter was also used to provide further information and clarity to several tables in the chapter.
\end{abstract}

Methods: In updating the CIG anaphylaxis guidance, VSWG conducted an environmental scan, a review of relevant literature and consulted international and Canadian experts and professional societies.

Results: The use of diphenhydramine hydrochloride as adjunctive treatment in the management of anaphylaxis in a community setting is no longer recommended. Other notable changes made to the chapter include the following: 1) retitled: "Anaphylaxis and other acute reactions following vaccination"; 2 ) inclusion of new tables: "Key distinguishing features of anaphylaxis and vasovagal syncope" and "Signs and symptoms of anaphylaxis"; and 3) updated tables: "Anaphylaxis management kit: recommended items" and "Dosage of intramuscular EPINEPHrine 1:1000 (1 mg/mL) solution, by age or weight".

Conclusion: The updated CIG chapter provides healthcare providers with further clarity in recognizing and managing anaphylaxis in community settings. The updated intramuscular epinephrine dosage table will aid in optimal epinephrine administration, while the revised guidance against the use of diphenhydramine hydrochloride will prevent its unnecessary stockpiling in preparation for potential mass vaccination clinics related to the coronavirus disease 2019 pandemic.
This work is licensed under a Creative Commons Attribution 4.0 International License.

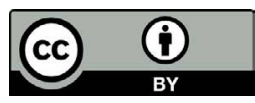

Affiliations

${ }^{1} \mathrm{NACl}$ Vaccine Safety Working Group Chair

2 Pharmacy Department, Children's Hospital of Eastern Ontario, Ottawa, ON

${ }^{3}$ Centre for Immunization and Respiratory Infectious Diseases, Public Health Agency of Canada, Ottawa, ON

${ }^{4}$ Division of Allergy and Immunology, Department of Pediatrics, Faculty of Medicine, University of British Columbia, Vancouver, BC

${ }^{5}$ British Columbia Children's Hospital Research Institute, Vancouver, BC

\section{*Correspondence:}

phac.naci-ccni.aspc@canada.ca

Suggested citation: Dayneka N, Jensen C, Hildebrand KJ on behalf of the National Advisory Committee on Immunization (NACl). Canadian Immunization Guide: "Anaphylaxis and other acute reactions following vaccination" chapter update. Can Commun Dis Rep 2020;46(11/12):384-6.

https://doi.org/10.14745/ccdr.v46i1112a04

Keywords: National Advisory Committee on Immunization, NACl, Canadian Immunization Guide, CIG, anaphylaxis, guidance

\section{Introduction}

The Canadian Immunization Guide (CIG) is a comprehensive resource on immunization for health professionals and vaccine program decision-makers. It is developed based on the evidence-based recommendations of the National Advisory Committee on Immunization (NACl).
$\mathrm{NACl}$ recommendations are developed by topic-specific working groups. The NACl Vaccine Safety Working Group (VSWG) is comprised of $\mathrm{NACl}$ members, liaison members and external experts, and is responsible for providing guidance on Part 2 
(Vaccine Safety) chapter revisions that pertain to vaccine safety monitoring in Canada, contraindications and precautions, and assessment and management of anaphylaxis.

Since the last chapter update, the World Allergy Organization (WAO) revised its recommendations on anaphylaxis management in the community. WAO now recommends that antihistamines should not be used in the initial treatment of anaphylaxis (1). The update of the chapter was also used to provide further information and clarity to several tables in the chapter.

\section{Methods}

In updating the CIG anaphylaxis guidance (2), NACI Secretariat conducted an environmental scan, a review of relevant literature and consulted international and Canadian experts and professional societies. The VSWG reviewed and discussed evidence pertaining to the following:

- The optimal position for individuals experiencing an anaphylactic reaction

- Canadian and international recommendations, guidelines and practices pertaining to the optimal site and dosage of epinephrine administration

- The use of diphenhydramine hydrochloride (Benadry $\left.\left.\right|^{\circledR}\right)$ in anaphylaxis management in the community

The updated guidance, including the removal of the adjunctive treatment recommendation and the table on epinephrine dose by age or weight, were presented to $\mathrm{NACl}$ for approval.

\section{Results}

In the case of anaphylaxis, VSWG clarified its recommendation to place individuals on their back (supine) and elevate their lower extremities. Until the anaphylactic reaction is fully managed, the vaccinee should remain in this recumbent position as fatality can occur quickly due to empty vena cava/empty ventricle syndrome (if the vaccinee stands or sits suddenly).

The VSWG confirmed that there are good data to support the conclusion that neither the deltoid nor the glutinous muscles should be the site for epinephrine administration. Epinephrine should always be provided intramuscularly in the mid-anterolateral aspect of the thigh (vastus lateralis) given that it has a large blood supply.

Following the review of evidence from WAO, the VSWG no longer recommends the use of antihistamines as adjunctive treatment in the management of anaphylaxis in a community setting. The use of adjunctive therapy was not considered to be appropriate in the community setting since the role of the vaccine provider in the management of post-immunization anaphylaxis is primarily to manage the patient (by providing epinephrine and monitoring) until emergency care arrives.

The VSWG also provided further guidance for intramuscular epinephrine dosage according to age, since many vaccine providers do not have access to a client's weight (e.g. there may be no scale in a pharmacy, mass immunization clinic, public health clinic, etc.). Although the literature supporting autoinjector administration of epinephrine to infants weighing less than $10 \mathrm{~kg}$ was found to be limited, the VSWG took the position that the benefits of epinephrine use in these individuals outweigh the risks, even though this use would be considered off-label in Canada.

The VSWG updated the epinephrine dosage table, which has been in use since June 2013 and was originally developed by the Immunization Action Coalition. The revised epinephrine dosing chart was adapted from the paediatric anaphylaxis algorithm of the Translating Emergency Knowledge for Kids (TREKK) $(3,4)$, which is a Canadian-based program dedicated to improving paediatric emergency care. In addition, age bands for dosing epinephrine were selected from the Australian Immunisation Handbook (5) as they corresponded well with the weight bands of the TREKK chart. This newly adapted table (Table 4: Dosage of intramuscular EPINEPHrine 1:1000 (1 mg/mL) solution, by age or weight) was reviewed and vetted by experts from the Canadian Society of Allergy and Clinical Immunology in August 2020.

Other notable changes made to the chapter include the following:

- New title: previously "Early vaccine reactions including anaphylaxis", now "Anaphylaxis and other acute reactions following vaccination"

- Inclusion of a new table: "Table 1: Key distinguishing features of anaphylaxis and vasovagal syncope"

- Inclusion of a new table: "Table 2: Signs and symptoms of anaphylaxis"

- Updated table: "Table 3: Anaphylaxis management kit: recommended items"

\section{Conclusion}

The updated CIG chapter provides healthcare providers with further clarity in recognizing and managing anaphylactic reactions in community settings. The development of the new intramuscular epinephrine dosage table will aid in optimal epinephrine administration, new recommendations on the use of diphenhydramine hydrochloride will prevent its unnecessary stockpiling in preparation for potential mass vaccination clinics related to the coronavirus disease 2019 pandemic. 


\section{Authors' statement}

CJ - Writing, original draft, review, editing

ND - Review, editing

$\mathrm{KH}-$ Review, editing

The Canadian Immunization Guide chapter, "Anaphylaxis and other acute reactions following vaccination" was revised by the National Advisory Committee on Immunization (NACl) Vaccine Safety Working Group and was approved by $\mathrm{NACl}$.

\section{Competing interests}

None.

\section{Acknowledgements}

Vaccine Safety Working Group members: N Dayneka (WG Chair), C Jensen (Public Health Agency of Canada [PHAC]), K Hildebrand, V Dubey, O Baclic (PHAC), J Gallivan, M Salvadori, A Pham-Huy, H Anyoti (PHAC), K Johnson (PHAC), B Seifert (external expert), K Top (external expert), B Law (external expert), W Alqurashi (external expert)

NACl members: C Quach (Chair), S Deeks (Vice-Chair), N Dayneka, P De Wals, V Dubey, R Harrison, K Hildebrand, C Rotstein, M Salvadori, B Sander, N Sicard and S Smith

Liaison representatives: LM Bucci (Canadian Public Health Association), E Castillo (Society of Obstetricians and Gynaecologists of Canada), A Cohn (Centers for Disease Control and Prevention, United States), J Emili (College of Family Physicians of Canada), M Naus (Canadian Immunization Committee), D Moore (Canadian Paediatric Society) and A Pham-Huy (Association of Medical Microbiology and Infectious Disease Canada)

Ex-officio representatives: J Gallivan (Marketed Health Products Directorate, Health Canada [HC]), E Henry (Centre for Immunization and Respiratory Infectious Diseases [CIRID], PHAC), M Lacroix (Public Health Ethics Consultative Group, PHAC), J Pennock (CIRID, PHAC), R Pless (Biologics and Genetic Therapies Directorate, HC), G Poliquin (National Microbiology Laboratory, PHAC) and T Wong (First Nations and Inuit Health Branch, Indigenous Services Canada)
The National Advisory Committee on Immunization acknowledges and appreciates the contributions of Dr. H Kim, Dr. J Upton, Dr. S Redpath, Dr. M Tunis and C Mauviel to this chapter revision.

\section{Funding}

The work of National Advisory Committee on Immunization is supported by the Public Health Agency of Canada.

\section{References}

1. Simons FE, Ebisawa M, Sanchez-Borges $M$, Thong BY, Worm M, Tanno LK, Lockey RF, El-Gamal YM, Brown SG, Park HS, Sheikh A. 2015 update of the evidence base: world Allergy Organization anaphylaxis guidelines. World Allergy Organ J 2015;8(1):32. DOl PubMed

2. National Advisory Committee on Immunization. Canadian Immunization Guide. Anaphylaxis and other acute reactions following vaccination (chapter). Ottawa (ON): PHAC; 2020. https://www.canada.ca/ en/public-health/services/publications/healthy-living/ canadian-immunization-guide-part-2-vaccine-safety/page4-early-vaccine-reactions-including-anaphylaxis.html

3. Translating Emergency Knowledge for Kids (TREKK). Pediatric anaphylaxis algorithm. Dec 2018. Version 1.1 (accessed 2020-06-28). https://trekk.ca/system/assets/ assets/attachments/339/original/2018-12-10_Anaphylaxis_ algorithm_v_1.1.pdf?1545083235

4. Translating Emergency Knowledge for Kids (TREKK). Bottom Line Recommendations: Anaphylaxis. December 2018, Version 1.2 (accessed 2019-07-09). https://trekk.ca/ system/assets/assets/attachments/338/original/2018-12-14_ Anaphylaxis_BLR_version_1.2.pdf?1545083199

5. Australian Government Department of Health. Australian Technical Advisory Group on Immunisation. Australian Immunisation Handbook. Canberra, Australia: ATAGI; 2018. https://immunisationhandbook.health.gov.au/ 